\title{
Mathematical Model of Proportional Spool Valve
}

\author{
Petr Chernus, Valery Sharovatov, Pavel Chernus \\ Baltic state technical university “VOENMEH” named after D.F. Ustinov, 1st Kranoarmeyskaya str. 1, 190005, \\ St-Petersburg, Russia
}

\begin{abstract}
This paper presents an improved mathematical model of the proportional spool valve flow characteristics. Valve spool dynamics and valve control system are not included in this model. Emphasis is made on consideration of variations of average values of gas flow temperature and friction factors when different flow types while the valve operating (subcritical, critical and supercritical flow) took place. The model is verified with mathematical modelling of gas flow in ANSYS Fluent.
\end{abstract}

Keywords: mathematical model; proportional valve; gas flow; flow characteristics; pressure ratio
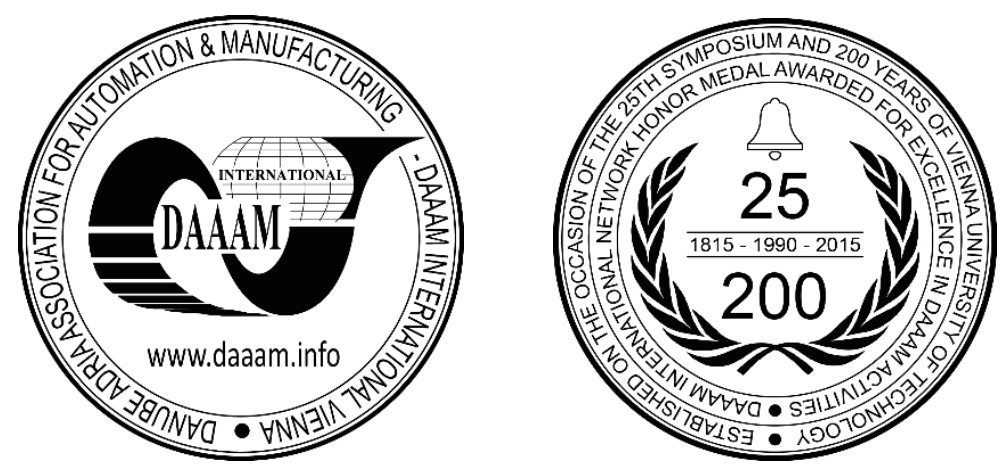

This Publication has to be referred as: Chernus, P[etr]; Sharovatav, V[alery] \& Chernus, P[avel] (2016). Mathematical Model of Proportional Spool Valve, Proceedings of the 26th DAAAM International Symposium, pp.0626-0632, B. Katalinic (Ed.), Published by DAAAM International, ISBN 978-3-902734-07-5, ISSN 1726-9679, Vienna, Austria DOI: $10.2507 / 26$ th.daaam.proceedings.085 


\section{Introduction}

Different type membranate elements, such as pneumatic artificial muscles (PAM) and bellow cylinders, have a great potential to be used as power actuators in robotics and automation due to their advantages as lightness, easy replacement, safe operation, etc. [1]. For motion control of membranate actuator it is necessary to know not only mathematical model of such element, but also mathematical model of a pneumatic valve. There are number of papers to date in which were designed mathematical models of PAMs [2-7] and bellows [8-9]. However many of them include simplified mathematical model of the valve. Should be mentioned that there are some papers that present mathematical models of pneumatic proportional valves used for precise pressure control [10]. Pneumatic proportional spool valve (fig. 1) presented in this paper is used for fast and precise gas flow control. In combination with an external position and pressure sensors and controllers, a precise and fast-acting pneumatic system could be created.

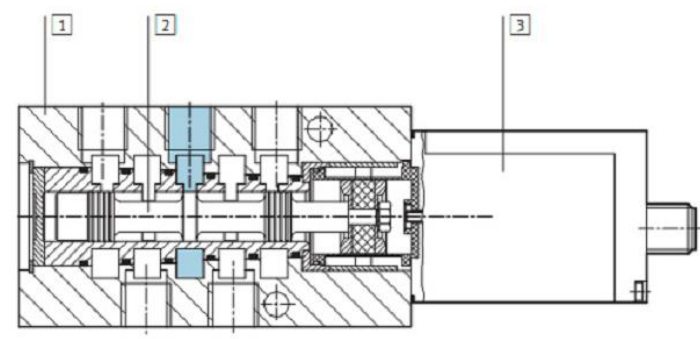

Fig. 1. Proportional pneumatic valve. 1 - housing, 2 - valve spool, 3 - housing for electronics

In this paper is presented improved mathematical model of flow rate of pneumatic proportional valve Festo MPYE-5-1/8LF-010-B. Spool dynamics and electro-magnetic part are not included in this model (see in previous papers of authors [11-12]). In previous research of the authors were not included in the model relation with varying average temperature of gas flow through the valve as well as were given only general recommendations of choosing of friction factor coefficient.

\section{Description of air flow through the valve}

[13]:

Pneumatic valve usually mathematically described as throttle mass flow rate through which one can calculate

$$
\begin{aligned}
& G=G^{*} \cdot f\left(\frac{p_{b}}{p_{a}}\right), \\
& G^{*}=0.039 \cdot \mu \cdot b \frac{p_{a}}{\sqrt{\theta_{a}}} x_{v}, \\
& f\left(\frac{p_{b}}{p_{a}}\right)=\left\{\begin{array}{c}
2 \sqrt{\left(1-\frac{p_{b}}{p_{a}}\right) \frac{p_{b}}{p_{a}}} \text {, when } \frac{p_{b}}{p_{a}}>0,528 \\
1, \text { when } \frac{p_{b}}{p_{a}} \leq 0,528
\end{array}\right.
\end{aligned}
$$

where $\mathrm{G}^{*}$ - means critical mass flow rate $(\mathrm{Ma} \approx 1)$;

$\mathrm{p}_{\mathrm{a}}$ - means constant input pressure;

$\mathrm{p}_{\mathrm{b}}$ - means constant output pressure;

$\mu-$ means flow coefficient of throttle aperture;

$\mathrm{b}$ - means aperture width;

$\theta_{\mathrm{a}}-$ means input gas temperature.

After air flow through the valve analysis, was developed equation system which describes mass flow rate through the valve [12]: 


$$
\left\{\begin{array}{c}
G_{1}=0.039 \cdot \mu_{1} \cdot b \frac{p_{i}}{\sqrt{\theta_{i}}} f\left(\frac{p_{1}}{p_{i}}\right) x_{3}, \\
G_{2}=0.039 \cdot \mu_{2} \cdot b \frac{p_{2}}{\sqrt{\theta_{2}}} f\left(\frac{p_{o}}{p_{2}}\right) x_{\mathrm{M}} \\
\Delta p=p_{1}-p_{2} \\
G_{1}=G_{2}=G \\
\Delta p=\xi \frac{v^{2}}{2} \rho \\
v=\frac{G}{\rho A_{c h}}
\end{array}\right.
$$

where $\mathrm{G}_{1}$ and $\mathrm{G}_{2}$ - means mass flow rates through first and second throttle apertures; $\mathrm{A}_{\mathrm{ch}}-$ means cross sectional area of the channel.

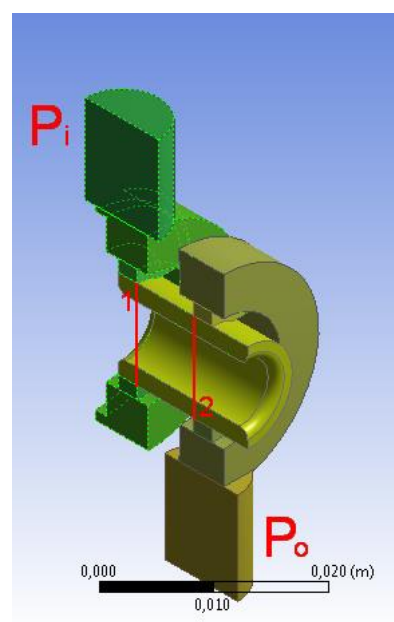

Fig. 2. Valve inner space longitudinal section

Valve inner space longitudinal section is shown in Figure 2. With numbers 1 and 2 are marked surfaces of air flow parameters (temperature, pressure, density, etc.) after and before corresponding throttle aperture. Then the solution of equation system (4) is the following:

$$
p_{1}=\frac{1}{2}\left(\begin{array}{c}
p_{i}-\left(\frac{\mu_{2}}{\mu_{1}}\right)^{2}\left(\frac{x_{m}}{x}\right)^{2} \frac{\theta_{i}}{\theta_{2}}\left(1+69 \xi \frac{\theta_{1}}{\theta_{i}} \mu_{1}^{2} \frac{b^{2} x^{2}}{A_{c h}^{2}}\right) p_{o}+ \\
+\sqrt{\left(p_{i}-\left(\frac{\mu_{2}}{\mu_{1}}\right)^{2}\left(\frac{x_{m}}{x}\right)^{2} \frac{\theta_{i}}{\theta_{2}}\left(1+69 \xi \frac{\theta_{1}}{\theta_{i}} \mu_{1}^{2} \frac{b^{2} x^{2}}{A_{c h}^{2}}\right) p_{o}\right)^{2}} \\
+4\left(\frac{\mu_{2}}{\mu_{1}}\right)^{2}\left(\frac{x_{m}}{x}\right)^{2} \frac{\theta_{i}}{\theta_{2}}\left(p_{o}+69 \xi \frac{\theta_{1}}{\theta_{i}} \mu_{1}^{2} \frac{b^{2} x^{2}}{A_{c h}^{2}} p_{i}\right) p_{o}
\end{array}\right)
$$

\section{Estimation of head loss coefficient}

Let begin with estimation of head loss coefficient $\xi$. This coefficient consist of following three coefficients: coefficient of so-called "minor losses" because of air flow turn and collision after the first throttle aperture pair $\xi_{1}$, coefficient of friction in valve channel $\xi_{2}$ and coefficient of losses because of air flow turn and stopping before the second pair of throttle apertures $\xi_{3}$. According to the parameters of channel length $\mathrm{L}$ and hydraulic diameter D air flow turn is about $45^{\circ}$, and losses coefficients $\xi_{1}=\xi_{3}=1$ [14]. The most complicate is to evaluate friction coefficient $\xi_{2}$ which could be calculated with Darcy-Weisbach equation [13]:

$$
\xi=4 f \frac{L}{D^{\prime}}
$$


where $\mathrm{f}$ - means fanning friction factor;

$\mathrm{L}$ - means channel length;

D - means channel hydraulic diameter.

For the given valve channel length and hydraulic diameter rate is the following:

$$
\frac{L}{D}=\frac{10 \mathrm{~mm}}{4 \mathrm{~mm}}=2.5
$$

Let evaluate fanning friction factor. In general, this coefficient depends on channel parameters, flow character and air flow velocity. Should be mentioned that air flow in channel is turbulent because two air flows after passing radial located throttle apertures collide (in figure 3 shown turbulence kinetic energy).

$\begin{aligned} & \text { Turbulence Kinetic Energy } \\ & \text { turbulent } \\ & 2.433 \mathrm{e}+003 \\ & 2.190 \mathrm{e}+003 \\ & 1.947 \mathrm{e}+003 \\ & 1.703 \mathrm{e}+003 \\ & 1.460 \mathrm{e}+003 \\ & 1.217 \mathrm{e}+003 \\ & 9.737 \mathrm{e}+002 \\ & 7.305 \mathrm{e}+002 \\ & 4.872 \mathrm{e}+002 \\ & 2.440 \mathrm{e}+002 \\ & 7.135 \mathrm{e}-001\end{aligned}$
$[\mathrm{~J} \mathrm{~kg}-1]$

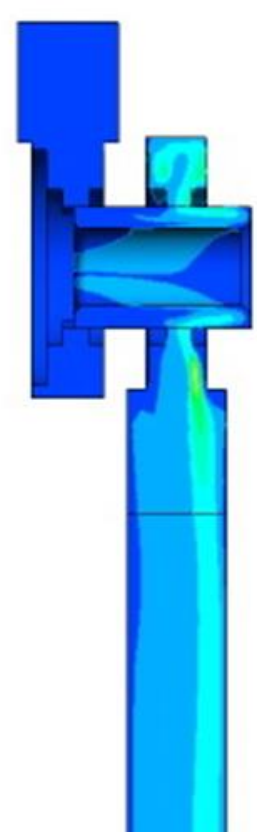

Fig. 3. Turbulence kinetic energy

Analyzing modelling results one can see that supersonic flow occurs mainly in downstream when small pressure ratio. Maximal air flow velocity in the valve channel is $\mathrm{v}=170 \mathrm{~m} / \mathrm{s}$. Then Reynolds numbers for air flow in channel in different cases are in a range of 1000 to 45000 . So far as air flow in the channel is turbulent and channel section is a ring, to calculate fanning friction factor one can use Blasius equation [13]:

$f=\frac{0.316}{4 \sqrt[4]{R e}}$

Values of friction coefficient $\xi_{2}$ have the following limits:

$0.054 \leq \xi_{2} \leq 0.14$

Because of relatively small values of friction coefficient and to simplify calculations, one can take $\xi_{2}=0.1$. As a result, a value of head loss coefficient could be taken constant and $\xi=2.1$.

\section{Evaluation of air flow temperature}

The main complexity in air flow temperature evaluation is that for precise solution it is necessary to solve Navier-Stokes equations. At the same time, air flows through the valve pretty fast, therefore for calculation of temperature could be used equations described adiabatic process, but pressure values $\mathrm{p} 1$ and $\mathrm{p} 2$ still unknown. For this reason and to simplify calculation procedure will be use empirical equations.

In figure 4 are shown contours of temperature when different values of input and output pressure and opening of the valve, besides in case b) take place supercritical flow. 


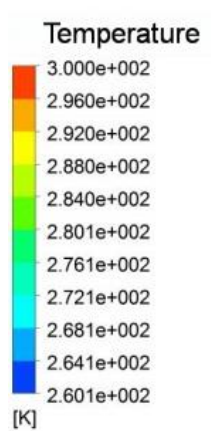
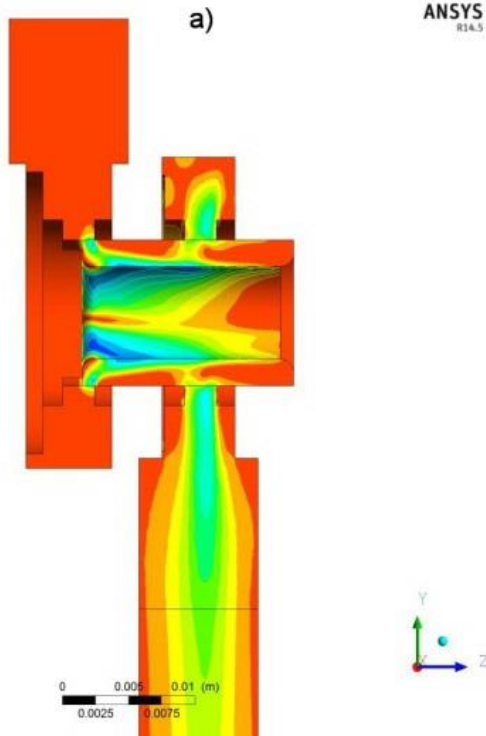

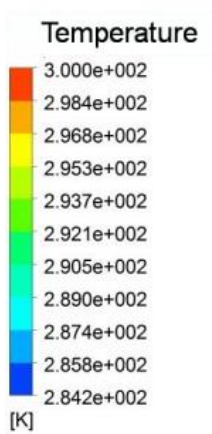
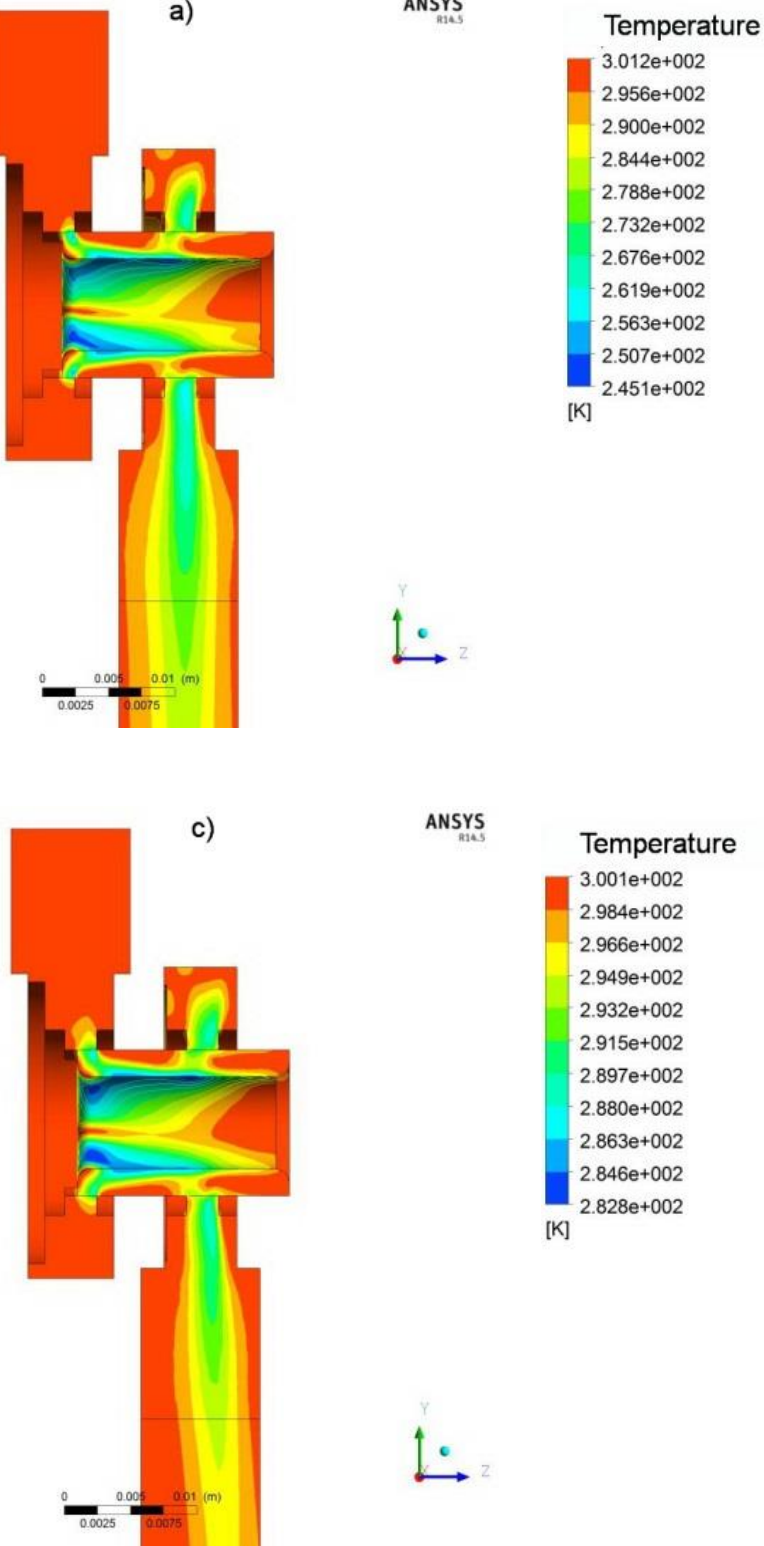

ANSYS
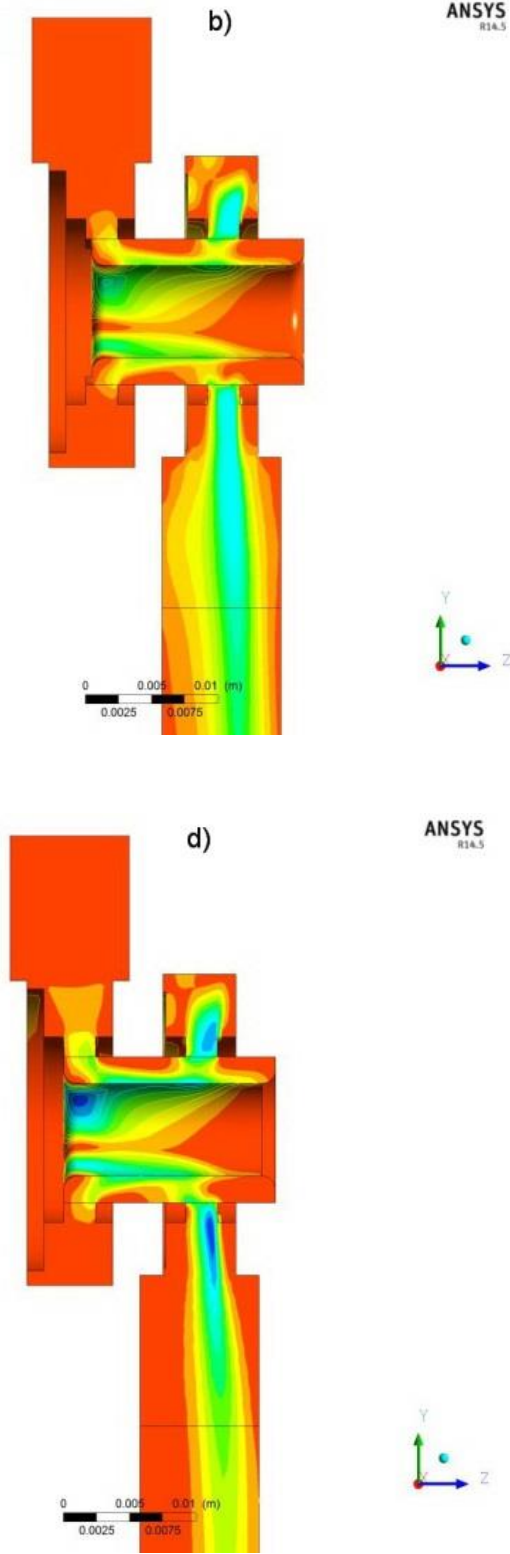

ANSYS

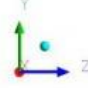

Fig. 4. Air flow temperature. a) valve open on $40 \%, p_{i}=5$ bar, $p_{o}=1$ bar; b) valve open on $80 \%, p_{i}=5$ bar, $p_{o}=1$ bar; c) valve open on $60 \%, \mathrm{p}_{\mathrm{i}}=5 \mathrm{bar}, \mathrm{p}_{\mathrm{o}}=3 \mathrm{bar} ; \mathrm{d}$ ) valve open on $100 \%, \mathrm{p}_{\mathrm{i}}=5 \mathrm{bar}, \mathrm{p}_{\mathrm{o}}=3 \mathrm{bar}$.

By modelling results was found out that average value of temperature $\theta_{1}$ mostly depends on input/output pressure ratio. This relation is not highly non-linear, so temperature value $\theta_{1}$ could be calculated with a help of the following linear empirical equation:

$$
\theta_{1}=\theta_{i}\left(1-0.075\left(1-\frac{p_{o}}{p_{i}}\right)\right)
$$

Average temperature value $\theta_{2}$ depends not only on input/output pressure ratio, but also on valve opening. There was developed the following equation to calculate temperature $\theta_{2}$ value:

$$
\theta_{2}=\theta_{i}-45 \cdot\left(\frac{p_{o}}{p_{i}}-1\right)^{2} \frac{x}{x_{m}}
$$

\section{Results}

In previous sections were evaluated values of average flow temperature $\theta_{1}$ and $\theta_{2}$ with equations (6)-(7) and head loss coefficient $\xi$. All other constants from equation (5) were found by authors in previous research [10]. Values of 
mass flow rate through the valve received by modelling results and with an equation (5) with different values of input and output pressure are shown in figures 5 and 6.

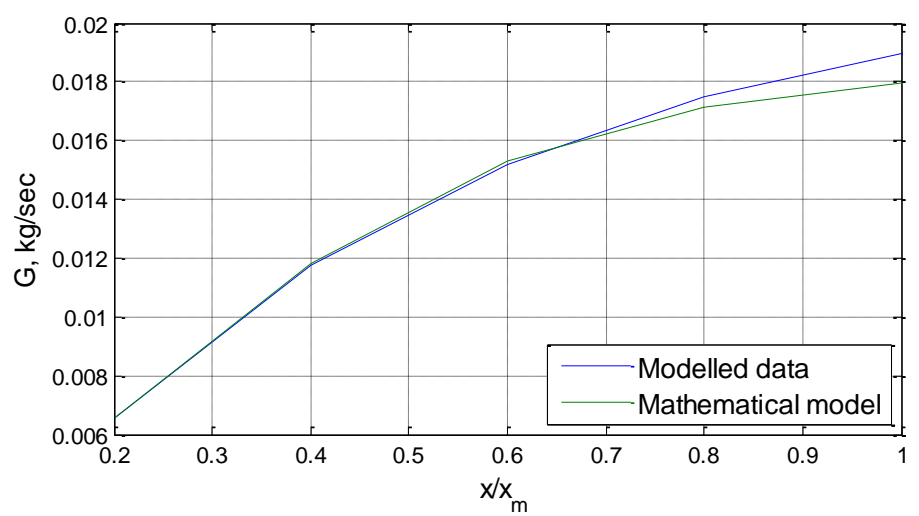

Fig. 5. Mass flow rate when $\mathrm{pi}=5$ bar, $\mathrm{po}=1 \mathrm{bar}$

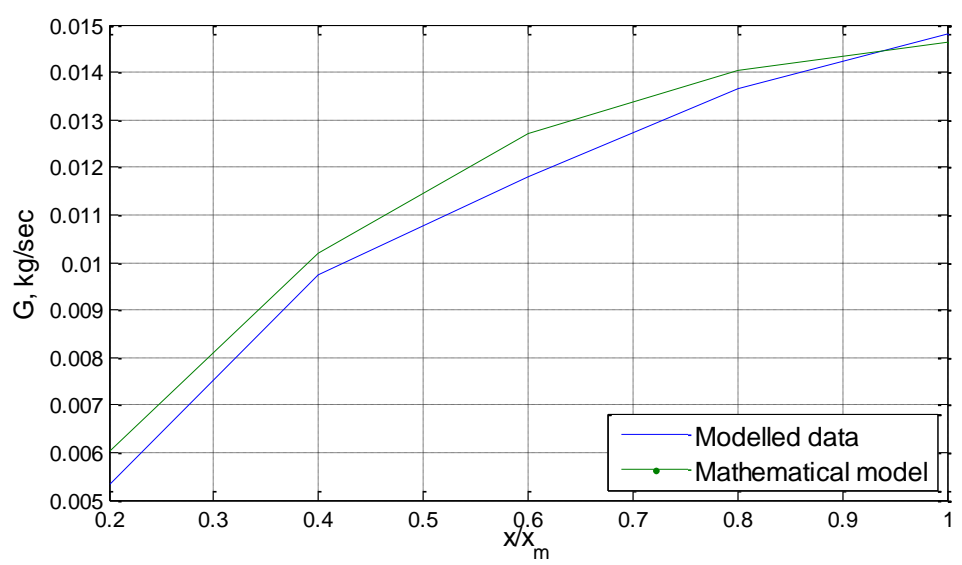

Fig. 6. Mass flow rate when $\mathrm{pi}=5$ bar, po $=3$ bar

Comparison of simulation and theoretical calculation shows us that the model works accurate (error is less than $6 \%$ ), especially when pressure ratio is small. The main reason of deviation is probably the fact that there were developed simplified equations for flow average temperature and head loss coefficient because of very complex flow process in the valve channel. Nevertheless introduction of these simplified equations decrease model error from $10-15 \%$ to $6 \%$ in comparison with previous research.

As a result was developed accurate mathematical model of a proportional pneumatic spool valve. The main advantage of this model is that the model based not on experimental data of particular valve, but on general gas dynamics theory. Consequently this model could be used for a class of pneumatic valves.

Finally use of developed improved mathematical model of valve flow rate together with membranate actuators models makes possible a design of fast and precise robotics and automation systems.

\section{Conclusion}

Improved mathematical model of flow rate of proportional pneumatic spool valve was presented in this paper. The main idea of creation of such model was consideration of air flow temperature average values variations and head loss coefficients variations to decrease model error. Development of the model included:

- General description of the air flow through the valve

- Evaluation of head loss coefficient

- Evaluation of air flow temperature variations

- Verifying results using modelling

Emphasis was made on developing of accurate easy-to-calculate universal mathematical model which could be used for a class of pneumatic valves. This model of the valve could be used together with the model of the pneumatic muscle or bellow cylinder to simulate different types of closed-loop systems, for example position system or active damping system.

The logical next step would be verification of received results by experimental data. Further research will be focused on verifying received results with help of experiment. 


\section{References}

[1]. Daerden, F., Lefeber, D.: Pneumatic Artificial Muscles: actuators for robotics and automation. European Journal of Mechanical and Environmental Engineering. Citeseer, 2002, issue 1, vol. 47, pp. 11-21

[2]. Loshitskiy, P.A., Sharovatov, V.T., Mathematical model of dual-acting force mambranate rodeless pneumocylinder, Mechatronics, Automation, Control, Moscow, 2012, №4, pp. 24-30.

[3]. J. Pitel, R. Neydorf, J. Borzikova, Arm position simulation of PAM based actuator, Annals of DAAAM for $2011 \&$ Proceedings of the 22nd International DAAAM Symposium, Katalinic, B. (ed.), DAAAM International Vienna, ISBN 978-3-901509-83-4, Vienna, 2011, pp. 0145-0146.

[4]. K. C. Wickramatunge, T. Leephakpreeda, Empirical modeling of dynamic behaviors of pneumatic artificial muscle actuators, ISA Transactions, Vol. 52, Issue 6, 2013, pp. 825-834.

[5]. S. Ganguly, A. Garg, A. Pasricha, S.K. Dwivedy, Control of pneumatic artificial muscle system through experimental modelling, Mechatronics, Vol. 22, Issue 8, 2012, pp. 1135-1147.

[6]. M. Tóthová, A. Hošovský, Dynamic Simulation Model of Pneumatic Actuator with Artificial Muscle, SAMI 2013, IEEE 11th International Symposium on Applied Machine Intelligence and Informatic, 2013, pp. 47-51.

[7]. M. Tóthová, J. Pitel', Dynamic Simulation of Pneumatic Muscle Actuator in Matlab/Simulink Environment, SISY 2014, IEEE 12th International Symposium on Intelligent Systems and Informatics, 2014, pp. 209-213.

[8]. V. Sharovatov, P. Chernus, Mathematical Model of a Strength Part of a Push Type Single-Acting Rodless Pneumatic Cylinder, Mechatronics, Automation, Control, №9, 2014, pp. 30-36.

[9]. Chernus Pavel, Sharovatov Valery. Dynamic Mathematical Model of Two-way Bellow Actuator. // ProcediaEngineering, Vol. 100, 2015, pp. 1040-1045.

[10]. Varga, Z., Honkola, P.-K., Mathematical model of pneumatic proportional valve, Journal of applied science in thermodynamics and fluid mechanics Vol.1, No. 1/2012.

[11]. P.P. Chernus, V.T. Sharovatov, Accounting for compressed gas properties in the mathematical model of a spool valve // Proceedings of higher educational institutions. Machine building, №12, 2014, pp. 22-29

[12]. Petr Chernus, Valery Sharovatov, Consideration of influence of peculiarities of compressed gas on mathematical model parameters of spool valve. // Procedia Engineering, Vol. 100, 2015, pp. 1046-1054.

[13]. Popov, D.N., Dynamics of hydraulic and pneumatic drives, Moscow, 2002.

[14]. Herz, E.B., Pneumatic devices and systems. Reference book, Moscow, 2010. 